\title{
Effective Protection for Copper Corrosion by Two Thiazole Derivatives in Neutral Chloride Media: Experimental and Computational Study
}

\author{
Yujie Qiang ${ }^{1}$, Shengtao Zhang ${ }^{1, *}$, Shenying $\mathrm{Xu}^{1}$, Lei Guo ${ }^{2}$, Nanxi Chen ${ }^{1}$, Ime B. Obot ${ }^{3}$ \\ ${ }^{1}$ School of Chemistry and Chemical Engineering, Chongqing University, Chongqing 400044, P R \\ China \\ ${ }^{2}$ School of Materials and Chemical Engieering, Tongren University, Tongren 554300, P R China \\ ${ }^{3}$ Center of Research Excellence in Corrosion, King Fahd University of Petroleum and Minerals, \\ Dhahran 31261, Saudi Arabia \\ *E-mail: stzhang_cqu@163.com
}

doi: $10.20964 / 110403147$

Received: 9 January 2016 / Accepted: 2 February 2016 / Published: 1 March 2016

\begin{abstract}
Two corrosion inhibitors for copper in neutral $\mathrm{NaCl}$ solution, 2-aminobenzothiazole (ABT) and 2amino-6-bromobenzothiazole (ABBT) were investigated by corrosion experiments and theoretical simulations. The results of weight loss and electrochemical experiments revealed that ABT and ABBT are efficient cathodic inhibitors with excellent inhibition efficiency (ABBT > ABT), which was further confirmed by field emission scanning electronic microscope (FESEM) observation. The adsorption of these molecules on copper surface was found to obey Langmuir adsorption isotherm. Moreover, the quantum chemical calculations and molecular dynamic (MD) simulation were used to investigate inhibition mechanism of studied inhibitors.
\end{abstract}

Keywords: Corrosion inhibitor, Adsorption, Copper, Electrochemical test, Quantum chemical calculation, Molecular dynamic simulation

\section{$\underline{\text { FULL TEXT }}$}

(C) 2016 The Authors. Published by ESG (www.electrochemsci.org). This article is an open access article distributed under the terms and conditions of the Creative Commons Attribution license (http://creativecommons.org/licenses/by/4.0/). 